\title{
PENGARUH MEDIA SIMULATOR CNC 2 AXIS TERHADAP HASIL BELAJAR MATA DIKLAT CNC DASAR SISWA DI SMK NEGERI 5 PADANG
}

\author{
THE INFLUENCE OF THE MEDIA SIMULATOR CNC 2 AXIS AGAINST \\ THE RESULTS OF THE STUDY EYE BASIC CNC TRAINING STUDENTS \\ IN SMK NEGERI 5 PADANG
}

\author{
Yogi Erwandi Candra ${ }^{(1)}$, Yufrizal A. ${ }^{(2)}$, Irzal ${ }^{(3)}$,Febri Prasetya ${ }^{(4)}$ \\ (1), (2),(3) Jurusan Teknik Mesin, Fakultas Teknik, Universitas Negeri Padang \\ Kampus Air Tawar, Padang 25131, Indonesia \\ yogierwandi.candra@yahoo.co.id \\ yufrizal@yahoo.com \\ irzal@gmail.com
}

\begin{abstract}
Abstrak
Tujuan penelitian ini adalah untuk melihat pengaruh/perbedaan hasil belajar mata diklat CNC dasar menggunakan media simulator CNC dibandingkan dengan metode konvensional yang berawal dari rendahnya pemahaman siswa terhadap mata diklat CNC dasar. Hal ini disebabkan oleh kurangnya fasilitas mesin CNC yang memadai untuk proses belajar mengajar, yang kemudian berdampak pada rendahnya hasil belajar siswa.

Penelitian ini menggunakan pendekatan quasi eksperimen dengan desain penelitian posttest only. Tempat penelitian di SMK Negeri 5 Padang. Subyek penelitian adalah siswa kelas 3 Mesin yang terdiri dari 2 (dua) kelas, kelas eksperimen (3M1) dengan jumlah siswa sebanyak 27 orang menggunakan media simulator CNC 2 Axis dan kelas kontrol (3M2) dengan jumlah siswa sebanyak 27 orang menggunakan media konvensional.

Hasil Penelitian membuktikan bahwa analisis uji-t antara kelas eksperimen dan kelas kontrol diperoleh $t_{\text {hitung }}=$ 5,118 sedangkan $t_{\text {tabel }}$ pada taraf signifikan 0,05 dengan $\mathrm{df}=27+27-2=52$ adalah $\mathrm{t}_{\text {tabel(52) }}=1,675$. Maka $\mathrm{t}_{\text {hitung }}>$ $\mathrm{t}_{\text {tabel }}(5,118>1,675), \mathrm{H}_{\mathrm{o}}$ ditolak sekaligus menerima $\mathrm{H}_{\mathrm{i}}$. Berdasarkan hasil analisis uji $\mathrm{T}$ tersebut dapat disimpulkan bahwa terdapat perbedaan yang signifikan, antara hasil belajar mata Diklat CNC dasar menggunakan media simulator CNC, dibandingkan dengan media konvensional.

Kata kunci: Media, Simulator CNC 2 Axis, hasil belajar, CNC Dasar, SMK Negeri 5 Padang.
\end{abstract}

\begin{abstract}
The purpose of this research is to look at the influence of learning outcome differences/eye training CNC CNC simulator using the media base as compared with conventional methods of originating from the low level of understanding of students against training CNC basics. This is due to the lack offacilities adequate to CNC machine the process of teaching and learning, which then resulted in a low learning outcomes students.

This research uses quasi experiment approach with posttest only design research. The place of research in SMK Negeri 5 field. The subject of research is the grade 3 engine that consists of two classes, the class experiment (3M1) and the number of students as many as 27 people using the media simulator CNC 2 Axis and the control class (3M2) and the number of students as many as 27 people using conventional media.

Results of the study prove that t-test analysis between the experimental and the control class obtained $t$ calculate $=5.118$ whereas $t$ tables in significant extent 0.05 with $d f=27+27-2=52$ is $t=$ table (52) 1.675 . Then $t$ calculate > t table $(5.118>1.675)$, Ho is rejected at once received the Hi. Based on the results of the analysis of the T-test can be concluded that there is a significant difference between the results of the study eye Training CNC CNC simulator using the media base, compared to the conventional media.

Key words: Media, Simulator CNC 2 Axis, CNC, learning Basic results, SMK Negeri 5 Padang.
\end{abstract}




\section{Pendahuluan}

Bangsa yang maju ditandai dengan pendidikan yang maju pula. Begitu pentingnya pendidikan, sehingga suatu bangsa dapat diukur apakah bangsa itu maju atau mundur dari pendidikan, sebab pendidikan merupakan proses mencetak generasi penerus suatu bangsa. Bagi suatu bangsa yang ingin maju, Pendidikan harus dipandang sebagai sebuah kebutuhan yang sama halnya dengan kebutuhan-kebutuhan lainnya seperti pangan, sandang, dan papan. Namun sangat miris rasanya melihat kondisi pendidikan di Indonesia pada saat ini. Berbagai permasalahan timbul seperti tenaga pendidik yang kurang profesional, kurang memadainya sarana dan prasarana penunjang pendidikan sehingga berdampak pada kualitas siswa yang masih jauh dari yang diharapkan.

Perkembangan teknologi saat ini juga membuat dunia pendidikan berkembang amat pesat, berbagai macam pembaharuan harus dilakukan untuk meningkatkan kualitas pendidikan, baik dalam pengembangan kurikulum, inovasi pembelajaran, serta pemenuhan sarana dan prasarana pendidikan. Untuk meningkatkan prestasi belajar siswa, maka guru dituntut untuk membuat pembelajaran lebih inovatif yang mendorong siswa dapat belajar secara optimal baik di dalam belajar mandiri maupun pembelajaran di kelas.

Penetapan standar proses pendidikan menjadi hal yang sangat penting dan strategis untuk pemerataan dan peningkatan kualitas pendidikan. Melalui standar proses pendidikan setiap guru beserta pengelola sekolah dapat menentukan bagaimana seharusnya proses pembelajaran berlangsung. Peraturan Pemerintah Republik Indonesia Nomor 19 Tahun 2005 tentang Standar Nasional Pendidikan, pada BAB VII (Sarana Prasarana), Pasal 42, Butir 1 menyatakan bahwa:

"Setiap satuan pendidikan wajib memiliki sarana yang meliputi perabot, peralatan pendidikan, media pendidikan, buku dan sumber belajar lainnya, bahan habis pakai, serta perlengkapan lain yang diperlukan untuk menunjang proses pembelajaran yang teratur dan berkelanjutan"

Menurut Azhar Arsyad (2010 : 26-27) media pembelajaran dapat memperjelas penyajian pesan dan informasi sehigga dapat memperlancar dan meningkatkan proses dan hasil belajar mengajar. Selain itu media pembelajaran juga dapat meningkatkan dan mengarahkan perhatian anak sehingga dapat menimbulkan motivasi belajar, interaksi lebih langsung antara siswa dengan lingkungannya, dan kemungkinan siswa untuk belajar sendiri-sendiri sesuai dengan kemampuan dan minatnya. Menurut Wina Sanjaya (2010 : 23) ada beberapa peran guru berkaitan dengan pemanfaatan media pembelajaran diantaranya sebagai berikut: 1) Guru perlu memahami berbagai jenis media dan sumber belajar beserta fungsi masing-masing media tersebut. Pemahaman akan fungsi media sangat diperlukan karna masin-masing media memiliki kharakteristik yang berbeda. 2) Guru dituntut untuk mampu mengorganisasi berbagai jenis media serta dapat memanfaatkannya sesuai dengan kebutuhan. Perkembangan teknolgi informasi menuntut setiap guru untuk dapat mengikuti perkembangan teknologi mutakhir.

Berdasarkan pendapat para ahli diatas dapat disimpulkan bahwa pemanfaatan media pendidikan menjadi suatu hal yang sangat penting dalam meningkatkan kualitas mutu pendidikan. Guru yang profesional akan mempersiapkan segala hal yang akan berdampak positif kepada peserta didik dan proses pembelajaran. Dalam penerapan media pembelajaran ini dituntut kemampuan guru memahami berbagai macam media yang tersedia, kemudian mampu memilih media yang tepat digunakan untuk mata pelajaran tertentu serta sanggup menyampaikannya dengan baik kepada peserta didik. Apabila hal tersebut telah dimiliki oleh guru, maka akan dapat membangkitkan keinginan dan minat belajar, membangkitkan motivasi dan rangsangan kegiatan pembelajaran, dan bahkan membawa pengaruh-pengaruh psikologis terhadap siswa.

Mata diklat CNC Dasar adalah salah satu mata diklat kejuruan pada jurusan teknik mesin yang mempelajari bagaimana cara membuat sebuah program CNC. Mata diklat CNC dasar juga mempelajari cara mengoperasikan mesin perkakas CNC dengan menggunakan sistem pengontrolan berbasis komputer. Program $\mathrm{CNC}$ adalah urutan kode-kode perintah berupa huruf dan angka yang diterjemahkan kedalam bahasa pemograman yang digunakan untuk menggerakkan MCU (machine Controlle Unit) guna membuat sebuah produk mesin perkakas.

Mempelajari mata diklat $C N C$ dasar ini membutuhkan konsentrasi yang tinggi, sehingga dengan cara konvensional siswa akan cepat bosan dan berdampak pada hasil belajar yang kurang memuaskan. Dengan adanya media simulator CNC, siswa dapat melihat langsung proses yang terjadi pada mesin CNC yang hampir menyamai mesin aslinya sehingga diharapkan pemahaman siswa dapat meningkat dibandingkan pembelajaran $\mathrm{CNC}$ secara konvensional.

Bertolak dari permasalahan diatas, maka peneliti tertarik untuk meneliti tentang, "Pengaruh Media Simulator CNC 2 Axis Terhadap Hasil Belajar Mata 
Diklat CNC Dasar Siswa Di Smk Negeri 5 Padang”.

\section{Metode Penelitian}

Jenis penelitian dalam penelitian ini menggunakan penelitian eksperimen. Menurut Suharsimi (2010 : 9) penelitian eksperimen adalah suatu cara untuk mencari hubungan sebab akibat (hubungan kausal) antara dua faktor yang sengaja ditimbulkan oleh peneliti dengan mengeliminasi atau mengurangi atau menyisihkan faktor-faktor lain yang mengganggu. Dalam penelitian ini, peneliti mengambil jenis pendekatan menurut rancangan penelitiannya yaitu menggunakan quasi experimental design atau penelitian desain eksperimen semu. Menurut Sumadi Suryabrata (2013:92) penelitian quasi experimental design atau penelitian desain eksperimen semu adalah untuk memperoleh informasi yang merupakan perkiraan bagi informasi yang dapat diperoleh dalam keadaan tidak memungkinkan untuk mengontrol atau memanipulas semua variable yang relevan.

Pada penelitian ini populasinya adalah keseluruhan siswa jurusan teknik mesin, di SMK negeri 5 Padang. Teknik sampel yang digunakan adalah teknik sampling acak. Menurut Husein Umar (2005: 82) "Pengambilan sampel secara acak adalah suatu metode pemilihan ukuran sampel dimana setiap anggota populasi mempunyai peluang yang sama untuk dipilih menjadi anggota sampel". Ada beberapa nama untuk menyebutkan teknik pemilihan sampling ini diantaranya adalah random sampling atau teknik acak. Pada teknik acak ini, secara teoritis, semua anggota dalam populasi mempunyai probabilitas atau kesempatan yang sama untuk dipilih menjadi sampel. Untuk mendapat responden yang hendak dijadikan sampel bahwa perlunya mengetahui jumlah responden yang ada dalam populasi Sampel penelitian yang digunakan peneliti adalah kelas 3M1 sebagai kelas eksperimen dan Kelas 3M2 sebagai kelas kontrol. Berdasarkan metode pengambilan sampel dengan menggunakan teknik sampling acak, maka diperoleh jumlah sampel 54 orang siswa.

Penelitian ini dilaksanakan di SMK Negeri 5 Padang yang beralamat di Jalan Beringin Raya Nomor 4, Lolong Belanti, Padang Utara, Kota Padang. Nomor Telp. (0751) 7053201. Waktu penelitian adalah pada bulan Februari tahun 2017.

Alat pengumpulan data pada penelitian ini adalah lembaran tes yang digunakan untuk mendapatkan data kuantitatif dalam penelitian. Menurut Suharsimi (2010:193) tes adalah serentetan pertanyaan atau latihan serta alat lain yang digunakan untuk mengukur keterampilan, pengetahuan intelegensi, kemampuan atau bakat yang dimiliki oleh individu atau kelompok. Tes yang digunakan dalam penelitian ini adalah post test. Post test diberikan setelah siswa mendapatkan perlakuan metode mengajar yang sudah direncanakan.
Analisis data yang digunakan pada penelitian ini adalah menggunakan uji prasayat analisis yaitu uji normalitas dan uji homogenitas. Setelah itu menguji apakah terdapat pengaruh/ perbedaan hasil belajar menggunakan media simulator CNC dibandingkan dengan media konvensional menggunakan uji hipotesis.

Uji normalitas ini bertujuan untuk melihat apakah sebaran data terdistribusi secara normal atau tidak. Uji normalitas dalam penelitian ini dilakukan dengan menggunakan uji one sample Kolmogorov Smirnov yang diolah dengan program SPSS dengan alpha $(\alpha)$ 0,05 dengan kriteria uji tersebut, yaitu: jika sig $\geq \alpha$ berarti data terdistribusi normal.

Uji homogenitas bertujuan untuk melihat apakah homogen atau tidak variasi sampel-sampel yang diambil dari populasi yang sama. Uji homogenitas dilakukan dengan menggunakanTest of Homogenity of Variances denganrumus (Sugiyono, 2008:275).

Uji hipotesis bertujuan untuk menentukan apakah kinerja siswa kelas XII teknik pemesinan di kelas eksperimen lebih baik dari pada kelas kontrol dalam membuat benda kerja dengan menggunakan mesin $\mathrm{CNC}$ milling, dengan hipotesis statistik:

Ho: $X_{1=X_{2}}$

$\mathrm{H}_{1:} X_{1}>X_{2}$

Keterangan

$M_{l}=$ Rata-rata skor tes kinerja siswa kelas eksperimen $M_{2}=$ Rata-rata skor tes kinerja siswa kelas kontrol Berdasarkan uji normalitas dan uji homogenitas variansididapat data berdistribusi normal dan kedua kelompok data memiliki varians yang sama, maka dalam pengujian hipotesis statistika yang digunakan adalah uji-t, uji-t yang digunakan adalah berdasarkan desain menggunakan randomized two-groups design, posttest only. Dengan persamaan yang digunakan oleh Liche, dkk (2011: 128) sebagai berikut:

Untuk mengetahui apakah media simulator $C N C$ berpengaruh terhadap hasil belajar mata diklat $C N C$ siswa di SMK Negeri 5 Padang, maka dihitung independent sample t-test, dengan rumus:

$$
t=\frac{M_{1}-M_{2}}{\sqrt{\frac{S S_{1}+S S_{2}}{n_{1}+n_{2}-2}}\left(\frac{1}{n_{1}}+\frac{1}{n_{2}}\right)}
$$

Keterangan:

$\begin{array}{ll}\mathrm{M}_{1} & =\text { rata-rata skor kelas eksperimen } \\ \mathrm{M}_{2} & =\text { rata-rata skor kelas kontrol } \\ \mathrm{SS}_{1} & =\text { sum of } \text { square kelas eksperimen } \\ \mathrm{SS}_{2} & =\text { sum of square } \text { kelas kontrol } \\ \mathrm{n}_{1} & \text { = jumlah subjek kelas eksperimen } \\ \mathrm{n}_{2} & \text { = jumlah subjek kelas kontrol }\end{array}$

Kriteria pengujian yaitu terima $\mathrm{H}_{\mathrm{o}}$ jika $-t_{1-\frac{1}{2} \infty}<t<t_{1-\frac{1}{2} \infty}$ dan tolak $H_{0}$ jika $t$ mempunyai 
harga lainnya, dimana $t_{1-\frac{1}{2} \infty}$ di dapat dari daftar distribusi $\mathrm{t}$ dengan derajat kebebasan $\left(d f=n_{1}+n_{2}-2\right)$ dengan taraf signifikan 0.05.

\section{Hasil dan Pembahasan}

Data pada penelitian ini berupa posttest. Posttest berupa gambar kerja yang akan dibuat program kerjanya oleh siswa. Posttest diberikan kepada siswa setelah mereka mendapatkan perlakuan. Berdasarkan hasil posttest didapatlah hasil kelas eksperimen dan kelas kontrol sebagai berikut :

Tabel 1 Deskripsi Kelas Eksperimen

\begin{tabular}{|c|c|c|}
\hline Subyek & Nilai $(\mathrm{X})$ & $\mathrm{X}_{1}^{2}$ \\
\hline 1 & 92 & 8521 \\
\hline 2 & 69 & 4793 \\
\hline 3 & 92 & 8521 \\
\hline 4 & 81 & 6524 \\
\hline 5 & 96 & 9246 \\
\hline 6 & 65 & 4275 \\
\hline 7 & 88 & 7825 \\
\hline 8 & 81 & 6524 \\
\hline 9 & 92 & 8521 \\
\hline 10 & 77 & 5917 \\
\hline 11 & 81 & 6524 \\
\hline 12 & 88 & 7825 \\
\hline 13 & 92 & 8521 \\
\hline 14 & 88 & 7825 \\
\hline 15 & 73 & 5340 \\
\hline 16 & 92 & 8521 \\
\hline 17 & 92 & 8521 \\
\hline 18 & 88 & 7825 \\
\hline 19 & 54 & 2899 \\
\hline 20 & 58 & 3328 \\
\hline 21 & 69 & 4793 \\
\hline 22 & 65 & 4275 \\
\hline 23 & 92 & 8521 \\
\hline 24 & 65 & 4275 \\
\hline 25 & 58 & 3328 \\
\hline 26 & 73 & 5340 \\
\hline 27 & 88 & 7825 \\
\hline$\sum$ & 2154 & 176154 \\
\hline
\end{tabular}

Tabel 2 Deskripsi Kelas Kontrol

\begin{tabular}{|c|c|c|}
\hline Subyek & Nilai $(\mathbf{X})$ & $\mathbf{X}_{\mathbf{1}}{ }^{\mathbf{2}}$ \\
\hline 1 & 96 & 9246 \\
\hline 2 & 69 & 4793 \\
\hline 3 & 77 & 5917 \\
\hline 4 & 58 & 3328 \\
\hline
\end{tabular}

\begin{tabular}{|c|c|c|}
\hline 5 & 88 & 7825 \\
\hline 6 & 65 & 4275 \\
\hline 7 & 58 & 3328 \\
\hline 8 & 85 & 7160 \\
\hline 9 & 81 & 6524 \\
\hline 10 & 69 & 4793 \\
\hline 11 & 69 & 4793 \\
\hline 12 & 62 & 3787 \\
\hline 13 & 62 & 3787 \\
\hline 14 & 73 & 5340 \\
\hline 15 & 92 & 8521 \\
\hline 16 & 77 & 5917 \\
\hline 17 & 38 & 1479 \\
\hline 18 & 96 & 9246 \\
\hline 19 & 62 & 3787 \\
\hline 20 & 77 & 5917 \\
\hline 21 & 23 & 533 \\
\hline 22 & 23 & 533 \\
\hline 23 & 19 & 370 \\
\hline 24 & 19 & 370 \\
\hline 25 & 23 & 533 \\
\hline 26 & 31 & 947 \\
\hline 27 & 12 & 133 \\
\hline$\sum$ & 1604 & 113180 \\
\hline & & \\
\hline
\end{tabular}

Hasil evaluasi hasil belajar siswa pada kelas eksperimen lebih tinggi dari pada siswa kelas kontrol, dapat disimpulkan bahwa pembelajaran menggunakan media simulator $\mathrm{CNC}$ berpengaruh terhadap hasil belajar siswa.

\section{A. Pengolahan Data}

\section{Uji Normalitas}

Berdasarkan hasil perhitungan SPSS 16 pada kolom Kolomogorov-Smirnov $Z$ dandapat diketahui bahwa nilai kelas eksperimen sebesar 1,175 dan kelas kontrol sebesar 0,947.

Diketahui jika sig $\geq 0,05$ berarti data berdristibusi normal.

Kelas Eksperimen : 1,175 $\geq 0,05$

Kelas Kontrol : 0,947 $\geq 0,05$

Maka dapat disimpulkan bahwa data pada variabel nilai siswa berdistribusi normal.

\section{Uji Homogenitas}

Pengujian homogenitas dilakukan untuk mengetahui apakah data dari kelas eksperimen dan kelas kontrol bersifat homogen atau tidak.Uji homogenitas ini menggunakan rumus pengujian kesamaan dua varians. Untuk varians skor tes kelas eksperimen $=$ 186,15 dan varians skor tes kelas kontrol $=688,1$. dari perhitungan pengujian varians diperoleh Fhitung 
$=3,698$ dengan $\mathrm{df}$ pembilang $\mathrm{k}-1=1 \mathrm{dan} \mathrm{dk}$ penyebut $\mathrm{n}-\mathrm{k}=52$ diperoleh nilai $\mathrm{F}$ pada tabel untuk $\alpha=5 \%$ adalah $F 0,05(1: 52)=4,03$ sehingga $F$ hitung < $\mathrm{F}$ tabel maka varians data dinyatakan homogen.

\section{Uji Hipotesis}

Berdasarkan dari hasil analisis uji-t terhadap skor tes kelas eksperimen dan kelas kontrol diperoleh t hitung $=5,118$ sedangkan $\mathrm{t}$ tabel pada taraf signifikan 0,05 dengan $\mathrm{df}=27+27-2=52$ adalah ttabel $(30)=$ 1,675. dengan $\mathrm{t}$ hitung $>\mathrm{t}$ tabel $(5,118>1,675)$.

Berdasarkan analisis di atas, maka dapat disimpulkan bahwa hasil belajar siswa kelas eksperimen penggunaan media simulator $\mathrm{CNC}$ untuk membuat program kerja pada mesin CNC TU 2A lebih baik dari siswa kelas kontrol dengan menggunakan metoda konvensional untuk membuat program kerja pada mesin CNC TU 2A. Dengan demikian hipotesis penelitian Ho ditolak dan Hi diterima yaitu "terdapat perbedaan hasil belajar mata diklat CNC Dasar menggunakan media simulator $\mathrm{CNC}$ dibandingakan dengan metode konvensional di SMK Negeri 5 padang."

\section{Kesimpulan dan Saran}

Hasil perhitungan t-test yaitu t table sebesar 1,675 yang lebih kecil daripada t hitung sebesar 5,118. Dengan demikian maka dapat disimpulkan bahwa terdapat perbedaan yang signifikan, antara hasil belajar mata diklat CNC dasar siswa menggunakan media simulator CNC 2 Axis dibandingkan dengan menggunakan media konvensional.

Peneliti memberikan beberapa saran terhadap penelitian tersebut, diantaranya:

1. Diharapkan kepada guru yang mengajar mata diklat CNC agar dapat menerapkan media simulator CNC kepada siswa yang telah diteliti

2. Mendapatkan hasil belajar yang lebih baik daripada menggunakan metode konvensional

3. Kepada pihak sekolah agar dapat memfasilitasi siswa agar dapat mempelajari juga simulator CNC secara mandiri. Akan lebih baik jika pembelajaran dilakukan dengan komputer yang mana setiap siswa dapat menginputkan program CNC yang telah dibuatnya sendiri. Jika tidak memungkinkan maka bisa menggunakan infokus saja.

4. Penelitian tentang pengaruh penggunaan media simulator CNC terhadap hasil belajar CNC ini perlu dilanjutkan dengan merancang program penelitian yang lebih baik dan lebih terprogram yaitu dengan materi pembelajaran yang lebih banyak serta mempersiapkan instrumen yang lebih teruji sehingga dapat menambah pengaruh yang lebih baik.

\section{Referensi}

Azhar Arsyad. 2010. Media Pembelajaran. Jakarta : Rajawali Pers Aksara.

Husein Umar, 2005. Metode Penelitian. Jakarta : Salemba Empat.

Liche Seniati, dkk. 2011. Psikologi Eksperimen. Jakarta: Indeks.

Republik Indonesia. 2005. Peraturan Pemerintah Republik Indonesia tentang Standar Nasional Pendidikan. Sekretariat Negara. Jakarta

Sumardi Suryabrata. 2013. Metodologi Penelitian. Jakarta : Rajawali Pers

Sugiyono. 2007. Metode Penelitian Pendidikan Pendekatan Kuantitatif, Kualitatif, dan R\&D. Bandung : Alfabeta.

Suharsimi Arikunto. 2007. Dasar-Dasar Evaluasi Pendidikan. Jakarta : Bumi Aksara

Wina Sanjaya. (2010). Strategi Pembelajaran Berorientasi Standar Proses Pendidikan. Jakarta : Prenada Media Group 